\title{
Cloud feedback in atmospheric general circulation models: An update
}

\author{
R. D. Cess, ${ }^{1}$ M. H. Zhang, ${ }^{1}$ W. J. Ingram, ${ }^{2}$ G. L. Potter, ${ }^{3}$ V. Alekseev, ${ }^{4}$ H. W. \\ Barker, ${ }^{5}$ E. Cohen-Solal, ${ }^{6}$ R. A. Colman, ${ }^{7}$ D. A. Dazlich, ${ }^{8}$ A. D. Del Genio, ${ }^{9}$ \\ M. R. Dix, ${ }^{10}$ V. Dymnikov, ${ }^{4}$ M. Esch, ${ }^{11}$ L. D. Fowler,${ }^{8}$ J. R. Fraser, ${ }^{7}$ V. Galin, ${ }^{4}$ \\ W. L. Gates, ${ }^{3}$ J. J. Hack, ${ }^{12}$ J. T. Kiehl, ${ }^{13}$ H. Le Treut, ${ }^{6}$ K. K.-W. Lo, ${ }^{9}$ B. J. \\ McAvaney, ${ }^{7}$ V. P. Meleshko, ${ }^{14}$ J.-J. Morcrette, ${ }^{15}$ D. A. Randall, ${ }^{8}$ E. Roeckner, ${ }^{11}$ \\ J.-F. Royer, ${ }^{13}$ M. E. Schlesinger, ${ }^{16}$ P. V. Sporyshev, ${ }^{14}$ B. Timbal, ${ }^{13}$ E. M. Volodin, ${ }^{4}$ \\ K. E. Taylor, ${ }^{3}$ W. Wang, ${ }^{16}$ and R. T. Wetherald ${ }^{17}$
}

\begin{abstract}
Six years ago, we compared the climate sensitivity of 19 atmospheric general circulation models and found a roughly threefold variation among the models; most of this variation was attributed to differences in the models' depictions of cloud feedback. In an update of this comparison, current models showed considerably smaller differences in net cloud feedback, with most producing modest values. There are, however, substantial differences in the feedback components, indicating that the models still have physical disagreements.
\end{abstract}

The most detailed models for estimating climate change caused by increasing greenhouse gases are three-dimensional general circulation models (GCMs). In 1989 we compared cloud feedback in 14 atmospheric GCMs [Cess et al., 1989], and this was extended in 1990 to include 19 models [Cess et al., 1990]; a broad spectrum of cloud feedbacks was noted. Most GCMs, however, are in a continual state of evolution, so those comparisons are not representative of current models. Here we present an updated comparison and show that GCMs are now

${ }^{1}$ Institute for Terrestrial and Planetary Atmospheres, Marine Sciences Rescarch Center, State University of New York, Stony Brook.

${ }^{2}$ Hadley Centre for Climate Prediction and Research, Meteorological Office, Bracknell, United Kingdom.

${ }^{3}$ Program for Clımate Model Diagnosis and Intercomparison, Lawrence Livermore National Laboratory, Livermore, California.

${ }^{4}$ Department of Numerical Mathematics, Russian Academy of Sciences, Moscow.

${ }^{5}$ Canadian Climate Centre, Downsview, Ontario, Canada.

"Laboratore de Météorologıe Dynamique, Paris.

${ }^{7}$ Bureau of Meteorology Research Centre, Melbourne, Victoria, Australıa.

${ }^{8}$ Colorado State University, Fort Collins.

${ }^{9}$ National Aeronautics and Space Administration, Goddard Institute for Space Studies, New York.

${ }^{10}$ Commonwealth Scientific \& Industrial Research Organisation, Division of Atmospheric Research, Mordialloc, Australia.

${ }^{1 !}$ Max Planck Institute for Meteorology, Hamburg, Germany.

${ }^{12}$ National Center for Atmospheric Research, Boulder, Colorado.

${ }^{13}$ Météo-France, Centre National de Recherches Météorologiques, Toulouse, France

${ }^{14}$ Voeıkov Main Geophysical Observatory, St. Petersburg, Russia.

${ }^{15}$ European Centre for Medium-Range Weather Forecasts, Reading, United Kingdom.

${ }^{16}$ Department of Atmospheric Sciences, University of Illinois, Urbana.

${ }^{17}$ Princeton University, National Oceanic and Atmospheric Administration, Geophysical Fluid Dynamics Laboratory, Princeton, New Jersey.

Copyright 1996 by the American Geophysical Union.

Paper number 96JD00822.

0148-0227/96/96JD-00822\$09.00 more consistent in their depictions of cloud feedback, with most models producing modest cloud feedback.

To understand cloud feedback, it is useful to first demonstrate how clouds affect the present climate. Figure 1 shows the Earth's global-mean radiation budget at the top of the atmosphere (TOA) and also a fictitious situation for which there are no clouds, but all else remains unchanged. Because clouds are bright, their presence increases reflection of shortwave (SW) radiation by $50 \mathrm{~W} \mathrm{~m}^{-2}$ (cooling), while the greenhouse effect of clouds results in a longwave (LW) warming of $30 \mathrm{~W} \mathrm{~m} \mathrm{~m}^{-2}$. Thus the net effect is a $20 \mathrm{~W} \mathrm{~m} \mathrm{~m}^{-2}$ cooling, conventionally expressed as a cloud radiative forcing (CRF) of $-20 \mathrm{Wm}^{-2}$ [Ramanathan et al., 1989; Harrison et al., 1990].

A common misconception is that because clouds cool the present climate, they will act to moderate global warming, i.e., a negative cloud feedback. It is, however, the change in CRF $(\triangle \mathrm{CRF})$, associated with a change in climate, that constitutes cloud feedback. For example, a doubling of atmospheric $\mathrm{CO}_{2}$ produces roughly a $4 \mathrm{~W} \mathrm{~m}^{-2}$ direct radiative forcing $(G)$ of the climate system, and if the ensuing climate change altered CRF from $-20 \mathrm{Wm}^{-2}$ to, say, $-16 \mathrm{Wm}^{-2}$, so that $\Delta \mathrm{CRF}=\mathrm{G}$ $(\triangle \mathrm{CRF} / \mathrm{G}=1)$, then $\Delta \mathrm{CRF}$ would amplify the direct radiative forcing by a factor of 2 (a twofold positive feedback). Zero cloud feedback corresponds to $\Delta \mathrm{CRF} / G=0$, while $\Delta \mathrm{CRF} / G$ $<0$ denotes negative feedback. Thus $\Delta C R F / G$ quantifies the net cloud feedback [Cess et al., 1989, 1990]. Since clouds have a net cooling effect and cloud amount decreases in models when the climate warms [Cess et al., 1990], one might expect a positive feedback. But even for models where cloud radiative properties are prescribed, this would only follow if the cloud reductions were uniform: in fact, the simulated cloud amount changes generally vary considerably with height and location and include regions of increase.

As before [Cess et al., 1989, 1990], we adopted $\pm 2 \mathrm{~K}$ sea surface temperature (SST) perturbations, with perpetual July simulations, as a surrogate climate change for the sole purpose of seeing how similar the response of the cloud forcing is in the different models. The extent of both sea ice and snow was fixed 


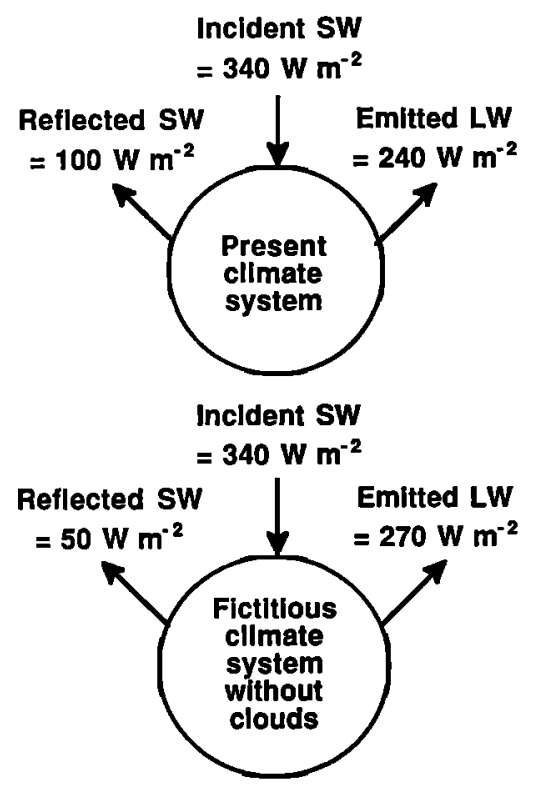

Figure 1. The Earth's top of the atmosphere radiation budget together with a fictitious situation in which there are no clouds, but all else remains unchanged.

to eliminate surface albedo feedbacks associated with ice/snow changes. Soil moisture was also fixed to eliminate excessive continental drying in the perpetual July simulations. The cloud feedback parameter, $\triangle \mathrm{CRF} / G$, is summarized in Figure 2a for the 1990 models [Cess et al., 1990]; the feedbacks range from modest negative to strong positive, with the strongest producing a feedback amplification factor of nearly 2.5 . The current models are listed in Table 1 (CCM2A and UKMOA are variants, as will be explained); relative to the 1990 models, they produce rather modest cloud feedback (Figure $2 \mathrm{~b}$ ). The mean $\triangle \mathrm{CRF} / G$ is reduced from 0.38 to 0.11 and the SD from 0.55 to 0.33 . The three successive versions of CCM demonstrated an interesting progression from strong positive feedback (CCM0) to rather modest positive feedback (CCM1) to modest negative feedback (CCM2). The 1990-to-current ECHAM models included two intermediate versions (not shown) that resulted in a four-model progression from strong positive feedback (Figure 2a) to weak positive feedback (Figure 2b). Another model that originally produced strong positive feedback (GISS) now has weak negative feedback.

Numerous changes were made throughout the four-model progression of the ECHAM GCM, e.g., inclusion of prognostic cloud water content, cloud optical properties related to cloud water content (i.e., interactive cloud optical properties), a different radiative transfer code, and a different convection scheme. Sensitivity studies showed that each of these changes contributed to small reductions in cloud feedback. But the most substantial reduction came from changing the cloud optical properties. The strong positive cloud feedback in the 1990 model version was largely an artifact of an improper choice of prescribed cloud droplet radius. The clouds were too bright which, combined with a large reduction in cloud amount for the warmer climate, produced a strong positive SW feedback. In the current ECHAM GCM the SW feedback is slightly negative (Figure $3 b$ ).

A large decrease in SW feedback was also the reason for the 1990-to-current reduction in net cloud feedback for the GISS
GCM. In the 1990 version, cloud optical thicknesses were prescribed so as to decrease with increasing cloud height. For a warmer climate the cloud heights increased, thus producing darker clouds (smaller optical depths). Combined with decreasing cloud amount, this caused strong positive SW feedback. In the current GISS GCM, which has prognostic cloud water and interactive cloud optical properties, cloud cover changes are more complex. But the largest impact is from a dramatic increase, for a warmer climate, in both the cloud water content (brighter clouds) and the amount of tropical cumulus anvils. This caused positive LW feedback and negative SW feedback, with the latter dominating so that the net feedback was slightly negative (Figure 3 ).

Thus to a large extent the 1990-to-current reductions in cloud feedback for the ECHAM and GISS GCMs were the result of incorporating interactive cloud optical properties. The same explanation does not, however, apply to the progressive CCM0-CCM1-CCM2 reductions, because all three employed prescribed cloud optical properties.

In many cases the current models produce similar cloud feedback for somewhat different reasons. The CCC model produces near-zero feedback because the LW and SW feedback components are negligible (Figure 3), while for ECMWF, DNM, and CSIRO, it is because of compensatory LW and SW feedbacks, with those for ECMWF being the reverse of DNM and CSIRO. CCM2 produces quite strong negative LW feed-
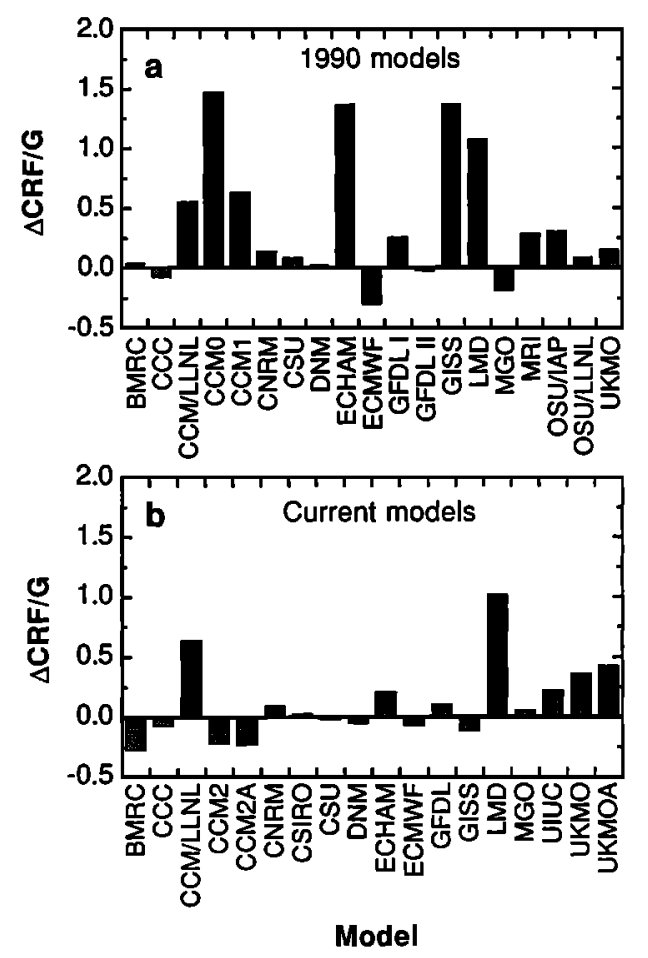

Figure 2. (a) The cloud feedback parameter, $\triangle \mathrm{CRF} / G$, as produced by the 19 atmospheric general circulation models (GCMs) used in the 1990 study (Figure 3). The model acronyms are those used in Figure 3. (b) The same as Figure 2a but for the current models. Several of the 1990 models are no longer in use (CCM0, CCM1, OSU/IAP, and OSU/LLNL). Of the current models, one (CCC) has undergone no revision, another (CCM/LLNL) only modest revision, two (CSIRO and UIUC) were not part of the 1990 comparison, and the rest have undergone either extensive or total revision. The MRI GCM is not a current participant. 
Table 1. List of General Circulation Models Used in the Present Study

\begin{tabular}{|c|c|}
\hline Model & Investigator \\
\hline $\begin{array}{l}\text { Bureau of Meteorology Research Centre, } \\
\text { (BMRC) }\end{array}$ & McAvaney, Fraser, Colman \\
\hline Canadian Climate Centre (CCC) & Barker \\
\hline $\begin{array}{l}\text { NCAR Community Climate Model, version } \\
2 \text { (CCM2 and CCM2A) }\end{array}$ & Zhang, Kiehl, Hack, Cess \\
\hline $\begin{array}{l}\text { NCAR Community Climate Model, version } \\
\text { 1; Lawrence Livermore National } \\
\text { Laboratory (CCM/LLNL) }\end{array}$ & Taylor \\
\hline $\begin{array}{l}\text { Centre National de Recherches } \\
\text { Météorologiques (CNRM) }\end{array}$ & Timbal and Royer \\
\hline $\begin{array}{l}\text { Commonwealth Scientific and Industrial } \\
\text { Research Organization, (CSIRO) }\end{array}$ & Dix \\
\hline Colorado State University (CSU) & Randall, Dazlich, Fowler \\
\hline $\begin{array}{l}\text { Department of Numerical Mathematics of } \\
\text { the Russian Academy of Sciences (DNM) }\end{array}$ & Galin, Dymnikov, Volodin, Alekseev \\
\hline $\begin{array}{l}\text { Max Planck Institute for Meteorology, } \\
\text { Hamburg (ECHAM) }\end{array}$ & Roeckner and Esch \\
\hline $\begin{array}{l}\text { European Centre for Medium-Range } \\
\text { Weather Forecasts (ECMWF) }\end{array}$ & Morcrette, Potter, Gates \\
\hline $\begin{array}{l}\text { Geophysical Fluid Dynamics Laboratory } \\
\text { (GFDL) }\end{array}$ & Wetherald \\
\hline $\begin{array}{l}\text { NASA Goddard Institute for Space Studies } \\
\text { (GISS) }\end{array}$ & Del Genio and Lo \\
\hline $\begin{array}{l}\text { Laboratoire de Météorologie Dynamique } \\
\text { (LMD) }\end{array}$ & Cohen-Solal and Le Treut \\
\hline Main Geophysical Observatory (MGO) & Meleshko and Sporyshev \\
\hline $\begin{array}{l}\text { University of Illinois at Urbana-Champagne } \\
\text { (UIUC) }\end{array}$ & Schlesinger and Wang \\
\hline $\begin{array}{l}\text { Hadley Centre for Climate Prediction and } \\
\text { Research, United Kingdom } \\
\text { Meteorological Office (UKMO and } \\
\text { UKMOA) }\end{array}$ & Ingram \\
\hline
\end{tabular}
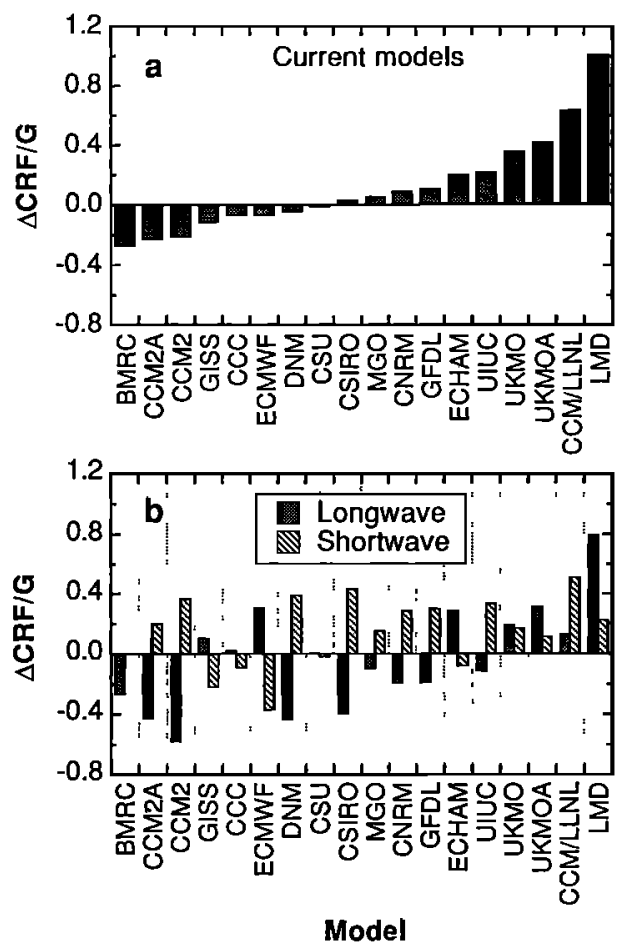

Figure 3. (a) The same as Figure $2 b$ but ordered in ascending values of the cloud feedback parameter $\Delta C R F / G$. (b) The same as Figure 3a but for the longwave and shortwave components of $\triangle \mathrm{CRF} / G$. back which is largely compensated for by positive SW feedback. And the two models with the strongest positive feedback do so for different reasons. For CCM/LLNL it is largely because of SW feedback, while for LMD it was mainly the result of positive LW feedback caused by a warming-induced increase in high cloud amount and emissivity.

Of particular interest is the agreement between CCM2 and CCM2A and between UKMO and UKMOA. Some recent observations [Ramanathan et al., 1995; Cess et al., 1995; Pilewskie and Valero, 1995] suggest that cloud SW absorption may be far higher than normally modeled, and this was incorporated into CCM2A and UKMOA by reducing the cloud single-scattering albedos to reproduce the overall relationship between surface and TOA SW cloud forcing apparently shown by observations [Ramanathan et al., 1995; Cess et al., 1995; Pilewskie and Valero, 1995]. Since this change alone made the models much darker than satellite observations indicate, they were then brought back into general agreement with observations by altering the critical relative humidities for cloud formation and other modifications. The "anomalous absorption" in CCM2A and UKMOA had significant impact on the globalmean SW absorption by the atmosphere, which in CCM2A increased by almost $30 \%$, from $67 \mathrm{~W} \mathrm{~m}^{-2}$ to $86 \mathrm{Wm}^{-2}$. However, in both cases, there was little overall impact on the cloud feedback (Figures $2 b$ and $3 b$ ).

This study has demonstrated that over the past 5 years there has been a substantial change in net cloud feedback as produced by atmospheric GCMs; there is now considerably less variation among the models. Most models produced modest 
feedback as estimated by the $\pm 2 \mathrm{~K}$ SST perturbations. Although substantial changes to GCM cloud parameterizations have been implemented since 1990 , it is not clear that a general increase in their accuracy is the sole explanation for the present trend toward convergence. It may be that current models are producing similar errors, while the earlier models produced different errors. But it is interesting to note that models that produced modest feedback in 1990 still do in their revised versions, while there has been a tendency toward modest feedback for those models that originally produced strong positive feedback.

On a final point, these model-produced cloud feedbacks may not be representative of how models would behave under realistic climate change conditions when they are coupled with interactive cryosphere and ocean models. Perpetual July simulations cannot be used for this purpose, nor can the uniformSST perturbations, because they do not account for changes in equator-to-pole temperature gradients or possible changes in longitudinal temperature gradients associated with actual climate change. The uniform-SST tests may not even rank models in the same order [Senior and Mitchell, 1993].

Acknowledgments. Valuable suggestions were provided by C. A. Senior. This study was performed under the auspices of the Environmental Sciences Division of the U.S. Department of Energy. Additional support was provided by the National Aeronautics and Space Administration, the National Science Foundation, the Bundesminister für Forschung und Technologie (Germany), the French Climate Program, and the Commission of European Communities.

\section{References}

Cess, R. D., et al., Interpretation of cloud-climate feedback as produced by 14 atmospheric general circulation models, Science, 245, 513-515, 1989.

Cess, R. D., et al., Intercomparison and interpretation of climate feedback processes in 19 atmospheric general circulation models, $J$. Geophys. Res., 95, 16,601-16,615, 1990.

Cess, R. D., et al., Absorption of solar radiation by clouds: Observations versus models, Science, 267, 496-499, 1995.

Harrison, E. F., et al., Seasonal variation of cloud radiative forcing derived from the Earth Radiation Budget Experiment, J. Geophys. Res., 95, 18,687-18,703, 1990.

Pilewskie, P., and F. P. J. Valero, Direct observations of excess solar absorption by clouds, Science, 267, 1626-1629, 1995.

Ramanathan, V., et al., Cloud-radiative forcing and climate: Results from the Earth Radiation Budget Experiment, Science, 243, 57-63, 1989.

Ramanathan, V., et al., Warm pool heat budget and shortwave cloud forcing: A missing physics, Science, 267, 499-503, 1995.

Senior, C. A., and J. F. B. Mitchell, Carbon dioxide and climate: The impact of cloud parameterization, J. Clim., 6, 393-418, 1993.

V. Alekseev, V. Dymnikov, V. Galin, and E. M. Volodin, Department of Numerical Mathematics, Russian Academy of Sciences, 32A Leninsky Prospect, Moscow, 117334, Russia.

H. W. Barker, Canadian Climate Centre, Downsview, Ontario, Canada M3H 5 T4.

R. D. Cess (corresponding author) and M. H. Zhang, Institute for Terrestrial and Planetary Atmospheres, Marine Sciences Research Center, State University of New York, Stony Brook, NY 11794.

E. Cohen-Solal and $\mathbf{H}$. Le Treut, Laboratoire de Météorologie Dynamique, 24 Rue Lhomond, 75231 Paris Cedex 05, France.

R. A. Colman, J. R. Fraser, and B. J. McAvaney, Bureau of Meteorology Research Centre, G.P.O. Box 1298K, Melbourne, 3001 Victoria, Australia.

D. A. Dazlich, L. D. Fowler, and D. A. Randall, Colorado State University, Fort Collins, CO 80523.

A. D. Del Genio and K. K.-W. Lo, National Aeronautics and Space Administration Goddard Institute for Space Studies, 2880 Broadway, New York, NY 10025.

M. R. Dix, Commonwealth Scientific \& Industrial Research Organisation, Division of Atmospheric Research, Private Bag 1, Mordialloc 3195, Australia

M. Esch and E. Roeckner, Max Planck Institute for Meteorology, Bundesstrasse 55, 20146 Hamburg, Germany.

W. L. Gates, G. L. Potter, and K. E. Taylor, Program for Climate Model Diagnosis and Intercomparison, Lawrence Livermore National Laboratory, Livermore, CA 94550.

J. J. Hack, National Center for Atmospheric Research, Boulder, CO 80307.

W. J. Ingram, Hadley Centre for Climate Prediction and Research, Meteorological Office, London Road, Bracknell, Berkshire RG12 2SY, United Kingdom.

J. T. Kiehl, J.-F. Royer, and B. Timbal, Météo-France, Centre National de Recherches Météorologiques, 42 Avenue G. Coriolis, 31057 Toulouse Cedex, France.

V. P. Meleshko and P. V. Sporyshev, Voeikov Main Geophysical Observatory, 7 Karbisheva Street, 194018 St. Petersburg, Russia.

J. J. Morcrette, European Centre for Medium-Range Weather Forecasts, Reading, Berkshire RG29AX, United Kingdom.

M. E. Schlesinger and W. Wang, Department of Atmospheric Sciences, University of Illinois, Urbana, IL 61801.

R. T. Wetherald, Princeton University, National Oceanic and Atmospheric Administration, Geophysical Fluid Dynamics Laboratory, Post Office Box 308, Princeton, NJ 08540.

(Received November 2, 1995; accepted March 5, 1996.) 